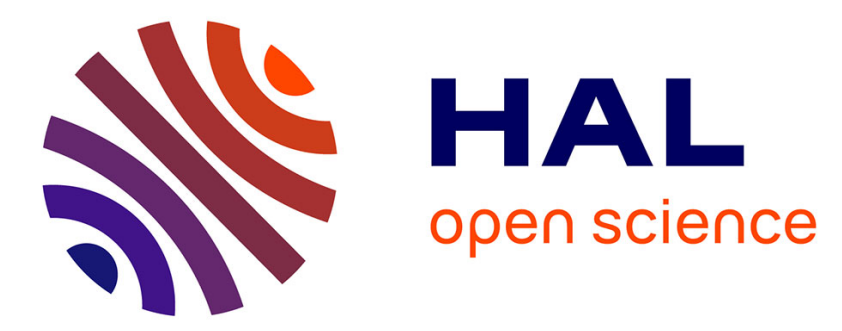

\title{
Users' Involvement in Value Co-Creation: The More the Better?
}

Benoît Desmarchelier, Faridah Djellal, Faïz Gallouj

\section{To cite this version:}

Benoît Desmarchelier, Faridah Djellal, Faïz Gallouj. Users' Involvement in Value Co-Creation: The More the Better?. European Management Review, inPress, 10.1111/emre.12365 . hal-02354136

\section{HAL Id: hal-02354136 https://hal.science/hal-02354136}

Submitted on 7 Nov 2019

HAL is a multi-disciplinary open access archive for the deposit and dissemination of scientific research documents, whether they are published or not. The documents may come from teaching and research institutions in France or abroad, or from public or private research centers.
L'archive ouverte pluridisciplinaire HAL, est destinée au dépôt et à la diffusion de documents scientifiques de niveau recherche, publiés ou non, émanant des établissements d'enseignement et de recherche français ou étrangers, des laboratoires publics ou privés. 


\title{
Users' involvement in value co-creation: The more the better?*
}

\author{
Benoit Desmarchelier, Faridah Djellal, Faïz Gallouj ${ }^{\dagger}$
}

July 29, 2019

\begin{abstract}
Literature on value co-creation often postulates that a greater degree of co-production increases the potential of value co-creation. To test this hypothesis, we build a computational model of value proposition inspired by March's model of organizational learning (1991[24]). The model allows to represent various cases of co-creation: (i) without co-production, (ii) with downstream co-production, and (iii) with upstream co-production. Repeated simulations are partly supporting the literature. On one hand, we find that deeper involvement of consumers into the value offering process increases the potential for value co-creation. One the other hand, we find that co-production can increase inequalities of satisfaction among consumers. Also, while scenarios with learning consumers offer the highest potential for value co-creation, a negative relationship emerges between the number of learning consumers and organizational performance.
\end{abstract}

Keywords: Value co-creation, organizational learning, modelling

*We thank the two anonymous reviewers for their very insightful comments on an earlier version of this paper. This paper draws on a research carried out within the Co-Val project, funded by the European Commission under the Horizon 2020 framework.

${ }^{\dagger}$ The University of Lille, France, Benoit.desmarchelier@univ-lille.fr; Faridah.Djellal@univlille.fr; Faiz.Gallouj@univ-lille.fr 


\section{Introduction}

All adaptive systems include performance measures used by microeconomic agents to make decisions (Holland and Miller, 1991[13]; Holland, 1975[12]). Companies are no different. They use a wide and evolving variety of such measures: profit, market share, return on equity, etc. A new one that is being advocated by scholars of service science is value co-creation, that is the satisfaction experienced by consumers while they are using the goods or services they bought (Vargo and Lusch, 2004[35]).

Vargo et al. (2008[36]) argue that previous performance indicators were based on prices, thus fundamentally on a criterion of "exchange value", while the co-creation approach focuses on the idea of "use-value". In this new framework, companies are not selling products, but a proposition of value consisting in "a clear, simple statement of the benefits, both tangible and intangible, that the company will provide" (Lanning and Michaels, 1988[16]). This promise becomes actual value once a consumer bought the product, experienced it and compared the resulting satisfaction felt with the initial promise (Vargo et al., $2008[36])$.

While use-value is necessarily co-created, the value offering does not need to be co-produced. Indeed, consumers can always formulate a judgement about an offering, regardless of their level of involvement in its making process. On this respect, Ballantyne et al. (2011[2]) and Osborne and Strockosch (2013[32]) - among others - put forth that potential of value co-creation is higher when co-production deepens. This hypothesis is debatable. Organizations are complex systems made of numerous and highly interdependent actors (Carley and Hill, 2001[5]), whose capacity of adaptation is also influenced by pre-existing routines (Nelson and Winter, 1982[30]). In a learning perspective, co-producing the value offering may confront employees to contradictions between consumers' aspirations and the practices and values of their organization. Such contradiction may hamper adequate customization of the offering, therefore reducing its use-value potential.

The relationship between co-production of the offering and co-creation of the use-value is thus not straightforward. It needs to be tested. In this paper, we investigate this question by building-on a simulation model of organizational learning and value co-creation in various configurations of coproduction.

Repeated simulations partly confirm the hypothesis found in the co-creation literature. Indeed, we find that deeper modes of co-production increase the potential of value co-creation. However, it also appears that co-production increases inequalities of satisfaction in cases where consumers are not learning from their interactions with the organization. Finally, we find a negative relationship between the number of learning consumers and the potential of value co-creation. Such learning indeed makes the environment more unstable for the firm. 
The rest of the paper is organized in four parts. In section 2, we review models of organizational learning and choose the one proposed by March (1991[24]). In Section 3, we adapt this model to account for value co-creation in various configurations of co-production. Section 4 presents and discusses simulation results, and Section 5 concludes the paper.

\section{Existing Models of Organizational Learn- ing}

In this section, we review existing models of organizational learning with the objective of finding one that can be amended to account for value co-creation.

In a learning perspective, organizations are adaptive systems: they adapt their decision rules - or routines (Nelson and Winter, 1982[30]) - when performance is deemed unsatisfactory. March and Olsen (1975[26]) conceptualize the organizational learning process in the form of a cycle in which individuals learn from observations of their environment. This learning produces individual actions, which lead to organizational actions, and ultimately to responses from the environment and so on. According to the authors, this cycle is often incomplete for many reasons: individuals can find it difficult to transform their learning into actions, these actions do not necessarily generate change at the organizational level, causalities in environmental reactions might be unclear, and individuals' observations of the environment are often subjective.

It follows that organizations are imperfectly co-evolving with their external environment (Dixon, 1999[9]; McKelvey, 1999[27]), and their employees (Kim, 1993[15]). Organizational learning is thus inherently a nested - multilevel and imperfect process. Such complexity renders the search process far from optimal (Cyert and March, 1963[7]) and path dependent (Levitt and March, $1988[21])$.

According to Lant and Mezias (1990[17]), models of organizational learning are built around three blocs: (i) an organization targets a certain level of performance, (ii) organizational change is triggered when performance does not reach the target, and (iii) change is achieved through a search process. A vast number of models of organizational learning exist in the literature, but not all are suitable for investigating interlinks with co-creation of value. Indeed, since co-creation opens up the learning process of the organization to consumers, the chosen model should include channels for co-evolutionary adaptation with them. Also, micro-foundations of the learning process at the employee's level seem necessary for representing such co-evolution.

In the framework proposed by Lant and Mezias (1990[17]), organizations are represented by four binary dimensions - thus accounting for 16 types of firms. Performance level of each dimension is set up at random at the start of a simulation, but changed once later on for testing firms' reaction to external shocks. Three search routines are modeled: (i) the "adaptive" search takes 
the form of a systematic search for a better fit organizational form, (ii) the "institutional" search consists in imitating better performing firms, and (iii) the "garbage can" search is a random search process. Finally, the target level of performance is defined by a dynamic equation.

This model has the advantage of adopting a co-evolutionary perspective. Indeed, the organization takes its competitors into account when searching, which influences in return these same competitors in their own searches. Lomi et al. (2010[23]) also propose a model in which an entrepreneur learns from its competitors. This kind of co-evolution is however not of the type we are aiming for. In a co-creation lens, attention should be given to co-evolution of organizational practices with users' needs, instead of with competitors. Another limit of Lant and Mezias's framework (1990[17]) is that the learning process being presented is not multilevel. Bruderer and Singh (1996[4]) put forth that such multi-level learning is absent in many models studying the evolution of ecologies of search strategies (Levinthal, 1997[19]; Lant and Mezias, 1992[18]; Mezias and Glynn, 1993[28]), in particular in those based on genetic algorithms, in which entities are often passive as change occurs from one generation to another within this class of models (Bruderer and Singh, 1996[4]; Mitchell, 1998[29]). A co-creation perspective rather requires to unveil how learning takes place within the organization (Payne et al., 2008[33]).

An unveiling of the micro-foundations of organizational learning is proposed by Carley and Hill (2001[5]). They define organizations as "composed of intelligent adaptive agents" (p. 63). The model takes the form of a "metanetwork" composed by two types of nodes - agents and knowledge bits - with links between them. This meta-network thus accounts for three inter-related sub-networks: a social network connecting the agents, an information network connecting knowledge nodes, and a knowledge network linking agents and knowledge. Agents acquire new knowledge by entering in interaction with others that have access to different knowledge. In this framework, establishment of new connexions define learning, and the organization's performance is measured by its degree of accuracy in hypothesizing on the composition of a string of binary numbers.

Carley and Hill (2001[5]) thus present organizational learning as a nested process occurring on intertwined networks, but without feedback loops with higher levels of aggregation. Hence, the organization itself does not influence agents' behaviors and trajectory in terms of knowledge acquisition - apart from the fact that this acquisition is conditioned by the other agents of the organization. Breslin (2014[3]) also proposes a micro-founded model of organizational learning in which employees are operating within social groups. In this framework, each employee makes a value proposition. The group's proposition is an average of its members' propositions, and the company's offering is then an average of all groups' propositions. The company's offering is then assessed by consumers on the basis of their preferences. The closer the proposition is to consumers' preferences, the higher the performance. This performance measure is close to the idea of value co-creation, but there is still no feedback between the organization and its employees: it is as if employees' 
learning was not conditioned by the organization's pre-existing routines.

For Dixon (1999[9]), this is the presence of a "storeroom where the mentos of the past are kept" (p. 48) that makes the process of organizational learning history-dependent. Organizations thus pass on norms, routines and "perceived truth" (March, 1991[24] p.74) to employees. Such feedback from the top is absent from the models reviewed so far, but it is at the heart of the one proposed by March (1991[24]). This model is composed of four elements:

- An "organizational code of received truth" (p. 74) composed of $m$ dimensions is initially set-up with null values.

- A vector of $m$ binary characteristics (i.e. 1 or -1 ) stands as the "reality".

- The organization is employing $n$ individuals, each with his/her vector of beliefs regarding the reality - initially filled at random with 0,1 or -1 values.

- A process of mutual learning in which every employee is adapting his/her beliefs to non-null dimensions of the code with a probability $p 1$. At the same time, the organization is adapting its code to the beliefs of the employees which are matching more closely the reality than does the code. For a given dimension, the code is modified in accordance with the belief of the majority $k$ of the well-informed employees with a probability $(1-p 2)^{k}$.

March (1991[24]) then augments this model to take into account employee's heterogeneity and turn-over, as well as instability of the environment - via random changes in the vector of reality. One of the main results is the importance of faster learning rate of the organization (i.e. high $p 2$ ) compared with the one of its employees (i.e. low $p 1$ ). Indeed, if employees are fast to get socialized to the code, then the organization cannot learn anymore from them. This relationship between $p 1, p 2$ and the knowledge level of the organizational code in March's model is exemplified in Figure 1. ${ }^{1}$

This model has been mobilized in many conceptual contributions (see for instance Levinthal and March, 1993[20], Crossan et al., 1999[6]), but - as stated by Kane and Alavi (2007[14] p. 798) "surprisingly little work has extended the original model". The present review has highlighted the qualities of this model with regards to both processes of learning and value co-creation. In a learning perspective, it incorporates a feedback loop between employees and their organization' memory, making the whole process complex and history-dependent, while in a value co-creation perspective, the organization's performance is based on correspondence with a vector of reality, which could be extended to represent consumers' preferences, as in Breslin (2014[3]). It is not denied that March (1991[24]) is also facing limitations. In particular, this model ignores social networks among employees within the organization, while such networks are playing a role in organizational learning (Carley and Hill, 2001[5]; Breslin, 2014[3]). This remark highlights that finding the right

\footnotetext{
${ }^{1}$ All models presented in this paper have been programmed in $C++$. Source codes can be obtained from the authors upon request.
} 
level of simplification is a difficult issue in model building. Since the discussion carried out thus far highlighted that core channels of organizational learning were the interplay between employees and their organization, as well as with the external environment, we propose to keep the question of social networks for future studies and to proceed by extending March's model.

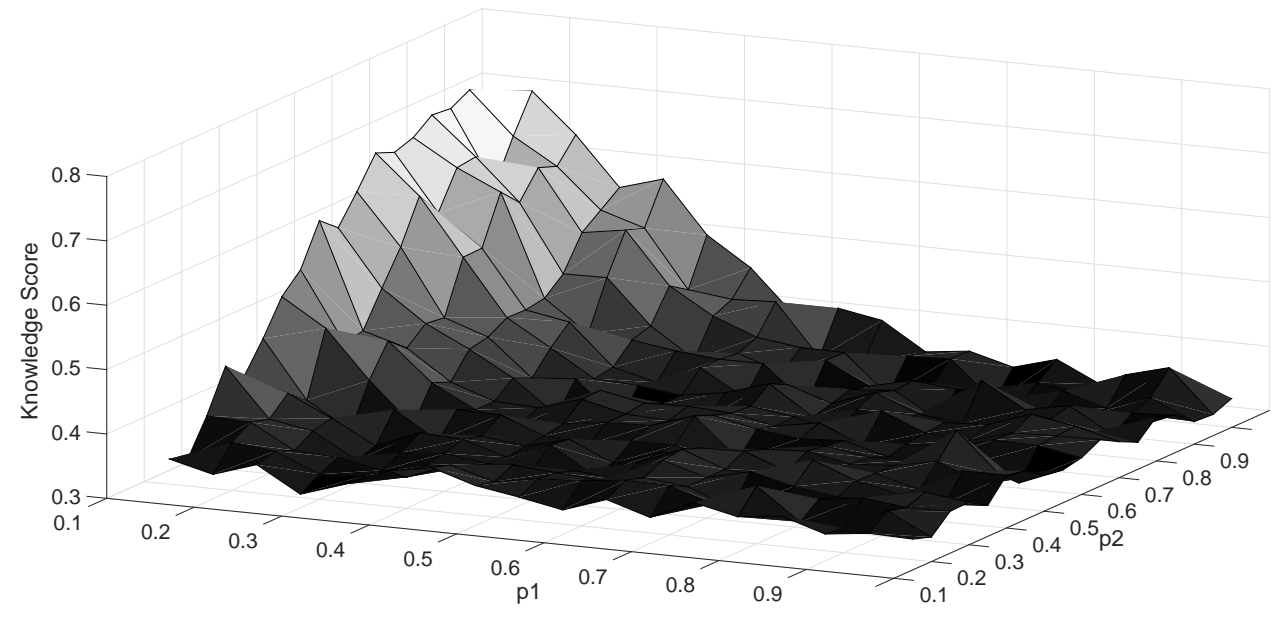

Figure 1: Relationship between employees' learning rate $(p 1)$, the organization's learning rate $(p 2)$ and its equilibrium knowledge score - i.e. the degree of correspondence between the organizational code and the reality - in March (1991[24]). Authors' calculations, averages over 30 simulations.

\section{A computational model of organizational learning and value co-creation}

The model we are proposing is a computational model, and it views organizations as composed of interacting agents. Such modeling technic, often referred to as "agent-based modelling" (Arthur, 2015[1] p.xv) allows to tackle non-linearity emanating from feedback loops occurring both among agents and with aggregate variables of the system being modelled. One advantage of agent-based modelling is that it allows to uncover microeconomic conditions which are sufficient for generating certain observable aggregate phenomena (Epstein and Axtell, 1996[11]). Such models hence constitute a valuable tool for theory discovery (Epstein, 2008[10]).

Aside from being a technical aid in performing complex computing, agentbased models permit to extend the number of questions to be addressed by management scholars and other social scientists. As such, March (2001[25]) highlights that these models allow to handle two new classes of problems, namely those of "ecological (contextual) complexity" and "historical (temporal) complexity" (p. xv-xvi). Respectively, these problems concern the linking of aggregate results with specific sets of interactions within populations - or 
ecologies - of microeconomic agents, and the study of path dependence, that is the dependence of current results to past courses of events. Note that these two problems are themselves defining characteristics of the notion of organizational learning (Levitt and March, 1988[21]; March and Olsen, 1975[26]).

In what follows, we augment March (1991[24]) with elements of value cocreation and co-production.

\subsection{Implementing value co-creation in March (1991)}

We propose to use the model of March (1991[24]) as a baseline for representing a process of value co-creation under various conditions of co-production. In an organizational learning perspective, value co-creation is a change in the performance measure used for triggering organizational change. Value co-creation starts with a proposition of value, or value offering. Compared with a goodsdominant logic (Vargo et al., 2008[36]) in which a firm focuses on producing and selling a material product, a value (or service-dominant) perspective imposes to "adopt a very sophisticated eye on the customer" (Levitt, 2004[22] p.139). The objective is to propose a "clear, simple statement of the benefits, both tangible and intangible, that the company will provide" (Lanning and Michaels, 1988[16] p. 53).

Arguably, such statement would be more easily understood by consumers if the organizational code is compatible with their aspirations. We thus propose to use the organizational code in March's model (1991[24]) as a proxy for value offering. We also replace the vector of reality by a population of individual consumers, each with his/her own vector of aspirations of $m$ dimensions - initially filled at random with 1 and -1 values. Without co-producing the value offering with consumers, the overall learning process is not affected by these modifications: employees still adopt non-null dimensions of the code with a probability $p 1$, and the code adopts the majority opinion among the better informed employees with a probability $(1-p 2)^{k}$, with $k$ the share of this opinion among the considered employees. Correspondence between employees' beliefs and consumers' aspirations is assessed relatively to majority's aspirations for each dimension $m$. The only difference with March's framework is thus that the vector of reality has been replaced by a vector of majority opinions among consumers. Hence, without co-production, the two models are equivalent, and we will see later in this text that they bring similar results (see the signs associated with $p 1$ and $p 2$ in Table 3 ).

In its present form, the model highlights that co-creation is merely a shift of perspective in which a unique reality is replaced by individual consumers' aspirations. So far, the organization in the model is not using this new diversity on the demand side for adapting its value offering. However, a finer knowledge of these aspirations could be gained - and used - through co-production, that we include in the model in the next subsection. 


\subsection{Co-production of the value offering}

As examplified in existing typologies, value offerings can be co-produced in different manners. A first one consists in involving consumers at the operational stage, mainly for gathering information about their needs and aspirations. A second manner consists in engaging consumers in the making of the value offering through reciprocal negotiations (Ballantyne et al., 2011[2]; Osborne and Strokosch, 2013[32]; Osborne et al., 2016[31]). Both types of co-production can have consequences on learning processes as they introduce new channels for co-evolutionary learning (Dixon, 1999[9]) between employees and consumers. Indeed, consumers' implication in the operational stage could modify employees' beliefs, while reciprocal negotiation could also trigger a learning process among consumers and affect their own aspirations - making them more or less able to understand value propositions made by the organization. We represent these two cases in the following.

\subsubsection{Organizational learning with downstream co-production of value}

In this configuration, employees are surveying consumers about their aspirations. This activity provides them with a new source of information, which can potentially enter in contradiction with information coming from the organization's existing value offering practices. We thus code two variants of the model: a conservative setting in which employees give priority to their socialization within the organization, and a progressive setting in which employees favor consumers' opinions over the organization's practices. Employees' learning in these two scenarios is detailed in Figure 2. 


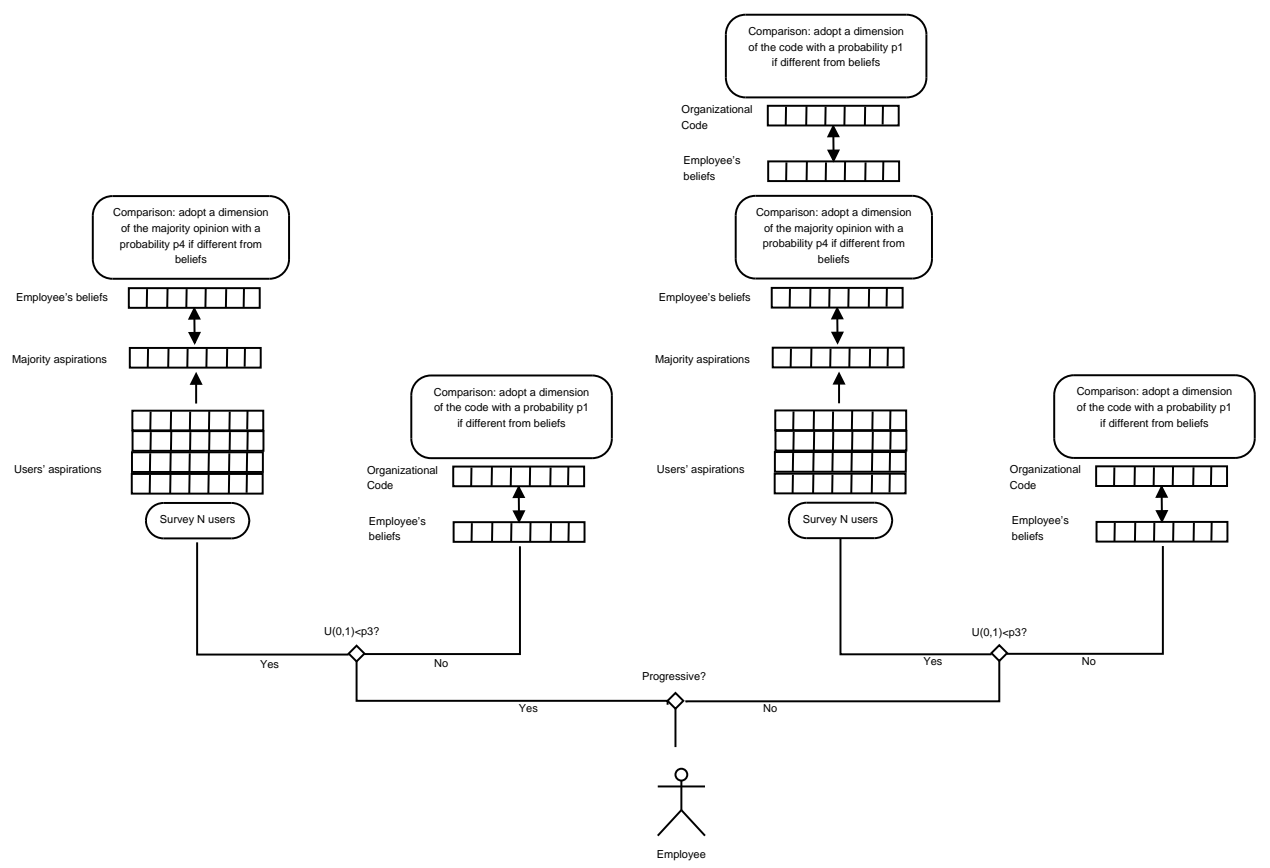

Figure 2:

Employee's search procedure with co-production.

In this Figure, $U(0 ; 1)$ stands for a random draw in a uniform distribution defined in the interval $[0 ; 1]$.

In a progressive setting (left side of Figure 2), each employee decides with a probability $p 3$ to survey $N$ consumers chosen at random ${ }^{2}$ - with $N$ the closest integer to a proportion $\delta$ of the entire population of consumers. By doing so, the employee builds a matrix of a size $N \times m$ which summarizes opinions of the surveyed individuals. Then he/she builds a vector representing the majority opinions emerging from this matrix on the basis of a simple majority rule. This vector is then compared with the employee's beliefs, and any difference is adopted by this later with a probability $p 4$. On the other hand, if consumers are not surveyed - that is when the condition $p 3$ is not met - then employees' learning procedure found in March (1991[24]) applies: each dimension of the value offering/ organizational code is adopted with a probability $p 1$.

In a conservative case (right side of Figure 2), employees' learning procedure is very similar to the one above, except that when consumers are surveyed, any majority belief adopted by the employee has a probability $p 1$ of being switched back into the organization's practice if different.

\subsubsection{Organizational learning with upstream co-production of value}

In this variant of the model, employees of the organization still survey a share $\delta$ of randomly chosen consumers and learn from them through the mechanisms

\footnotetext{
${ }^{2}$ Higher $p 3$ values indicate a more systematic consumers surveying by the organization.
} 
triggered by parameters $p 3$ and $p 4$ (see Figure 2). However, consumers are not anymore just sharing information about their aspirations. They now engage in a knowledge exchange process in which they get to know employees' beliefs. Access to such knowledge initiates a learning process among consumers, which we summarize in Figure 3.

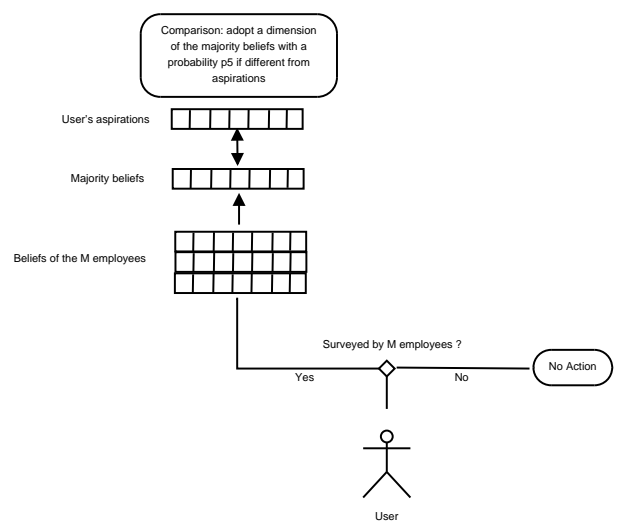

Figure 3: Employee's search procedure with co-production.

For a given consumer, learning occurs only when he/she has been surveyed by at least one employee during the current time step. In this case, a matrix of size $M \times m$ - with $M$ the number of contacting employees - is built by the consumer. ${ }^{3}$ A simple majority rule allows to obtain a vector of majority beliefs among these employees. The consumer then compares these majority beliefs with his/her own aspirations. In case of a difference, employees' majority belief is adopted by the consumer with a probability $p 5$.

Because of this new channel of learning, consumers are now taking an active part into the organization's learning system, which takes the form of two retroactive loops: the first loop is the one found in March's model (1991[24]) between the organization and its employees, the second loop of learning is between employees and consumers. These loops are simultaneous, which makes the overall outcome of the model difficult to predict. There is for instance a risk that employees adopt consumers' aspirations, while consumers adopt simultaneously the employees' beliefs. In this configuration, there would be an exchange and adoption of opinions, without making the value offering any closer to consumers' aspirations. However, such a situation is unlikely for two reasons. First, employees are controlling the direction of the learning process : if they are progressive, then the organization's value offering would approach aspirations of consumers, while in presence of conservative employees, consumers' aspirations are the ones that would adapt to the company's offering. Secondly, independently of employees' attitude (i.e. progressive or conservative), events are not necessarily equally likely in the model. Indeed, if for instance $p 3$ and $p 4$ are higher than $p 5$, then employees would learn more from consumers than the opposite. Attention should hence be given to parameters'

\footnotetext{
${ }^{3} \mathrm{~A}$ consumer might be contacted by several employees in cases of repeated buying, or when employees from different work units of an organization conduct distinct consumers' surveys.
} 
influence on the performance of the firm when analysing outputs of the model.

\section{Simulation Results}

Like in Vargo et al. (2008[36]), we define the organization's performance in a co-creation context as the degree of matching between its proposition of value and a vector of majority aspirations among consumers. This vector is of size $m$, and each of its dimension is filled-in with the opinion shared by the majority of the consumers. By doing so, we make the assumption that the closer the match, the higher the potential for value co-creation. This performance is comparable to an average degree of consumers' satisfaction. Consumers' initial aspirations, as well as employees' initial beliefs, are all setup at random.

This section starts with the analysis of the overall dynamics of the simulated organization's performance. Then, we investigate parameters' influence over this performance in all co-production configurations. Finally, we explore the incidence of co-production on the dispersion of consumers' satisfaction.

\subsection{General behavior of the model}

Examples of single simulation runs in different scenarios are provided in Figure 4. In these simulations and subsequent ones, the organization has 30 employees, there are 100 consumers, and $m=100$ (i.e. the number of dimensions of the value offering, of consumers' aspirations and of employees' beliefs). ${ }^{4}$

\footnotetext{
${ }^{4}$ Trials with different numbers of consumers have shown that the numbers of agents do not influence simulation results.
} 


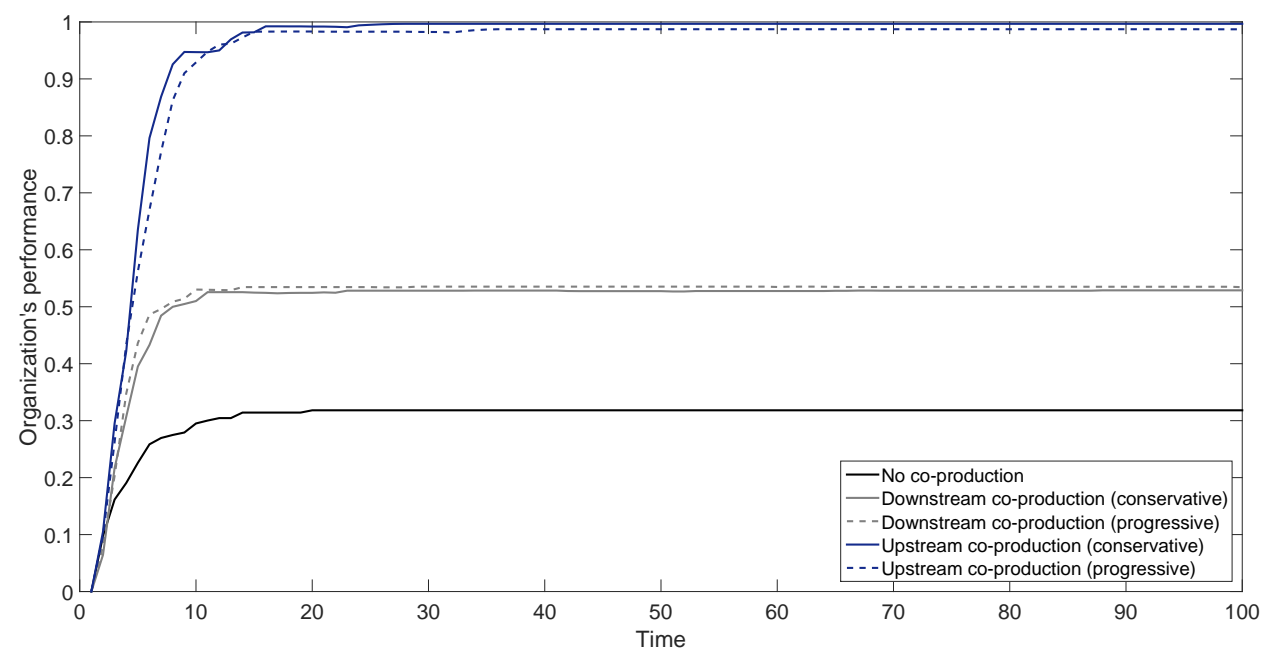

Figure 4: Evolution of the organization's performance in single simulation runs. Parameters are chosen as follows: March Case $-p 1=0.5, p 2=0.5$; Downstream co-production cases - $p 1=0.5, p 2=0.5, p 3=0.7, p 4=0.7, \delta=0.5$; Upstream co-production cases - $p 1=0.5, p 2=0.5, p 3=0.7, p 4=0.7, p 5=0.7, \delta=0.5$.

We observe in Figure 4 that modes of co-production seem to have significant influence on the organization's performance, since cases of upstream co-production allow to attain equilibrium levels of performance that are close to 1 , against around 0.5 and 0.3 for cases of downstream co-production and without co-production, respectively. These first simulation results are giving support to the hypothesis of higher co-creation when co-production deepens. Note however that, for each scenario, we have to test for the influence of all combinations of parameters. Also, because of the number of parameters, sensitivity analyses with $3 D$ graphs like the one displayed in Figure 1 is not a tractable option. Instead, since we observe the emergence of equilibrium levels of performance long before $t=50$ in Figure 4, we propose to analyze the model's outputs with the following Monte Carlo procedure, performed for each scenario: ${ }^{5}$

- Draw parameters values at random in the intervals defined in Table 1.

- Run a simulation 50 time steps.

- Records the equilibrium performance level at $t=50$ as well as parameters values.

- Repeat 5000 times. $^{6}$

Descriptive statistics of the resulting performance levels are provided in Table 2. Average equilibrium performance increases from 0.371 in the scenario without co-production, to above 0.53 and 0.92 with downstream and upstream

\footnotetext{
${ }^{5}$ Similar procedures for analyzing ouputs of agent-based models can be found in other papers, see for instance Pyka and Fagiolo (2007[34]), and Desmarchelier and Fang (2016[8]).

${ }^{6}$ Regression results were found to be unaffected by the number of simulations above 3000 repetitions.
} 
co-production, respectively. This first observation is supporting the hypothesis according to which co-production increases the (potential for) value cocreation (Ballantyne et al., 2011[2]; Osborne and Strokosch, 2013[32]). Interestingly, employees' attitude (progressive or conservative) towards consumers' aspirations is having at best only a marginal influence on the organization's performance. Also, standard deviation of performance levels is the lowest in cases of downstream co-production. This result had to be expected, because in this configuration employees are gathering information about consumers' aspirations, which are maintained unchanged throughout simulation runs. High kurtosis in all scenarios indicates that distributions of performance levels are highly peaked. Interestingly, these distributions exhibit fat tails in the lower values in all co-production scenarios (see the negative skewness coefficients in Table 2), while the fat tail is in upper values of performance when there is no co-production. It is thus possible to find higher performance without co-production in some single simulation runs, which shows the importance of using a repeated procedure prior to analyzing simulation results.

\begin{tabular}{ccl}
\hline Parameter & Value & Definition \\
\hline$p 1$ & {$[0.1,0.9]$} & Rate at which employees are learning from the organization. \\
$p 2$ & {$[0.1,0.9]$} & Learning rate of the organization. \\
$p 3$ & {$[0.1,0.9]$} & Probability to survey consumers. \\
$p 4$ & {$[0.1,0.9]$} & Rate at which employees are learning from consumers. \\
$p 5$ & {$[0.1,0.9]$} & Rate of consumers' learning. \\
$\delta$ & {$[0.1,0.9]$} & Share of consumers surveyed by employees. \\
\hline
\end{tabular}

Table 1: *

Parameters values

\begin{tabular}{cccccc}
\hline \multirow{2}{*}{ No co-production } & \multicolumn{2}{c}{ Downstream co-production } & \multicolumn{2}{c}{ Upstream co-production } \\
Conservative & Progressive & Conservative & Progressive \\
\hline Mean & 0.371 & 0.533 & 0.534 & 0.928 & 0.960 \\
Median & 0.361 & 0.535 & 0.536 & 0.979 & 0.990 \\
$\sigma$ & 0.047 & 0.008 & 0.007 & 0.099 & 0.076 \\
Kurtosis & 3.270 & 2.193 & 3.178 & 1.224 & 7.589 \\
Skewness & 1.850 & -1.483 & -1.568 & -1.492 & -2.802 \\
Min & 0.272 & 0.492 & 0.496 & 0.531 & 0.519 \\
Max & 0.524 & 0.550 & 0.549 & 1 & 1 \\
\hline
\end{tabular}

Table 2: *

Descriptive statistics of the organization's performance obtained through Monte Carlo experiment.

\subsection{Assessing parameters' influence on organizational performance}

We now move to the study of the influence of parameters values on the organization's levels of performance. For doing so, we regress equilibrium performance levels over parameters values in each scenario. Results are provided 
in Table 3. We note at first that the constant term is increasing when coproduction deepens. This constant term provides an estimate of the average organizational performance at time $t=50$ when all parameters have minimum values. Note however that these minimum values are set-up at 0.1 (see Table 1) and that we are at $t=50$, so a learning process has already taken place. We can thus interpret constant terms in Table 3 as the equilibrium level of the average performance of the organization in presence of a minimum learning.

With regards to the functioning of the learning process itself, it is evident that the relationship between employees' socialization rate $(p 1)$, the organization's learning rate $(p 2)$ and performance levels is affected by the introduction of co-production. Indeed, taking the no co-production case as a benchmark, the negative influence of $p 1$ is weakened in downstream co-production thanks to the appearance of the new learning channel. $p 1$ is even having a positive influence on the organization's performance when employees are progressive. This is because, in this configuration, employees' learning from existing organizational practices is complementing their learning from consumers (see Figure 2). In cases of upstream co-production, consumers are also learning from employees, hence their aspirations are now dynamic. It follows that the organization needs to gather information about consumers, hence again the negative role of $p 1$. In such a dynamic environment, quick adaptation of the value offering is a necessity, hence the relatively high $p 2$ coefficient compared with downstream co-production.

Regarding the influence of information gathering on organizational performance, coefficients associated with parameters $p 3, p 4$ and $\delta$ are all positive in downstream co-production. This result is consistent with the hypothesis that greater co-production increases value co-creation. Things are however different in upstream co-production, that is when consumers are learning as well from their interactions with employees. In this configuration, $p 3$ and $p 4$ are having even greater positive impact on performance, but $\delta$ - the share of consumers surveyed by employees - is now having a negative effect. This phenomenon is due to the fact that $\delta$ is the parameter that triggers consumers' learning, thus it renders the external environment more unstable: the higher $\delta$, the larger the number of learning consumers. When consumers are learning, they adopt employees' beliefs with a probability $p 5$ - which is having a positive effect on performance - but employees are in the meantime learning about consumers' aspirations. Since both sides are learning simultaneously, there is a risk that both are exchanging their respective beliefs, without getting any closer from each other. The surveying of consumers should thus be used with parsimony, hence the negative $\delta$ in upstream co-production. It is therefore appearent that in-depth co-production is not necessarily the best option for the organization when confronted to learning consumers. 


\begin{tabular}{cccccc}
\hline & \multirow{2}{*}{ No co-production } & \multicolumn{2}{c}{ Downstream co-production } & \multicolumn{2}{c}{ Upstream co-production } \\
& & Conservative & Progressive & Conservative & Progressive \\
\hline Const. & $0.374(* * *)$ & $0.519(* * *)$ & $0.520(* * *)$ & $0.833(* * *)$ & $0.869(* * *)$ \\
$p 1$ & $-0.057(* * *)$ & -0.0006 & $0.002(* * *)$ & $-0.069(* * *)$ & $-0.026(* * *)$ \\
$p 2$ & $0.053(* * *)$ & $0.004(* * *)$ & $0.005(* * *)$ & $0.018(* * *)$ & $0.027(* * *)$ \\
$p 3$ & & $0.004(* * *)$ & $0.005(* * *)$ & $0.016(* * *)$ & $0.053(* * *)$ \\
$p 4$ & & $0.013(* * *)$ & $0.008(* * *)$ & $0.199(* * *)$ & $0.106(* * *)$ \\
$p 5$ & & & $0.044(* * *)$ & $0.044(* * *)$ \\
$\delta$ & & $0.009(* * *)$ & $0.008(* * *)$ & $-0.019(* * *)$ & $-0.025(* * *)$ \\
$R^{2}$ & 0.206 & 0.297 & 0.267 & 0.358 & 0.238 \\
\hline
\end{tabular}

Table 3: *

Robust regression estimates of the influence of parameters on the equilibrium performance of the organization in the simulated scenarios.

$* * *$ statistically significant at $1 \%$

So far, we have measured the organization's performance on the basis of the correspondence between its value offering and majority aspirations of consumers. In this sense, high performance does not prevent some consumers to be disappointed with the value offering. We thus propose to assess the merits of our various scenarios with respect to the dispersion of users' satisfaction.

\subsection{Co-production and users' satisfaction}

For a given consumer, satisfaction is measured by the degree of correspondence between his/her aspirations and the value offering. When all consumers' satisfaction levels are known, it is possible to compute a standard deviation of it. At each repetition of the Monte Carlo experiment, we compute and record standard deviation of consumers' satisfaction at $t=50$. This provides us with 5000 values of dispersion in consumers' satisfaction per scenario. Distributions of these values are provided in Figure 5.

In Figure 5, higher standard deviations (measured on the horizontal axis) mean greater inequalities among consumers. Taking the scenario without co-production as a benchmark, we observe that downstream co-production has a tendency to generate higher dispersion in users' satisfaction. Basically, consumers who have been surveyed by employees are satisfied by the value offering, while the others remain disappointed. Hence, despite a greater overall performance in the downstream case compared to when there is no coproduction (see Tables 2 and 3), this type of co-production can be inadequate, especially if the organization is a public administration whose objective is to treat citizens equally.

Upstream scenarios are producing a wider range of standard deviation values of consumers' satisfaction, but they are virtually always inferior to those produced by the other scenarios, including the one without co-production. Involving consumers into the learning process thus appears as the surest way to improve equality of treatment among them. 


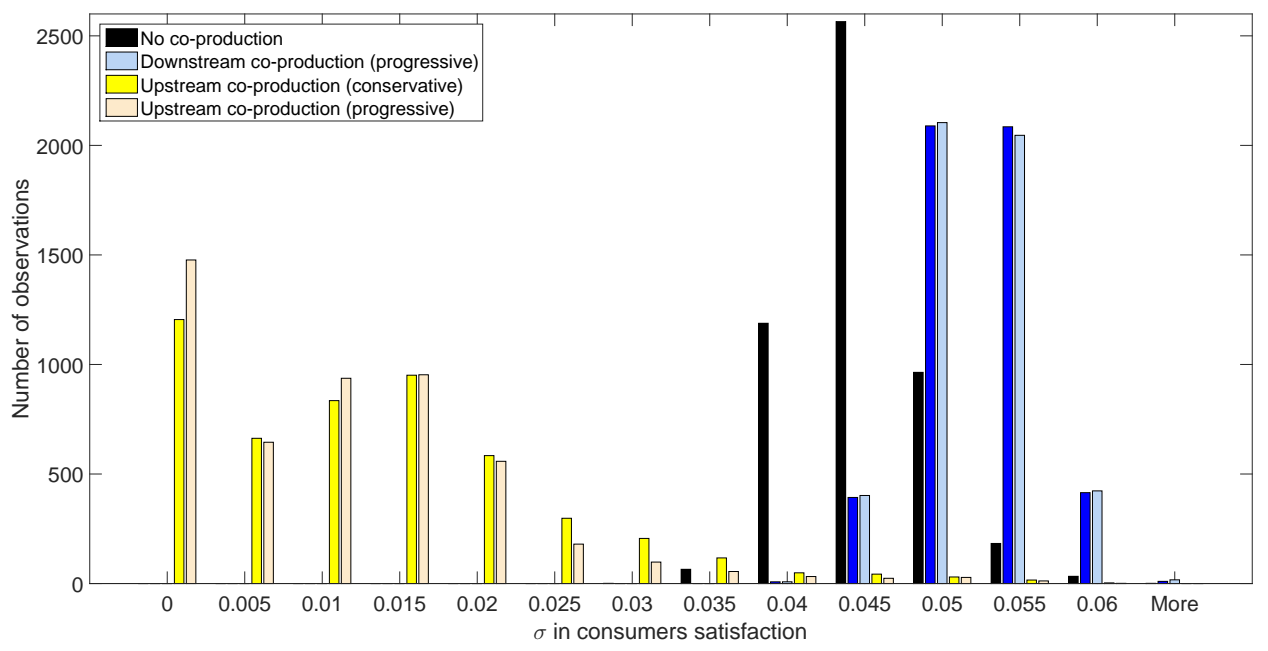

Figure 5: Distributions of the standard deviations in consumers' satisfaction per scenario

\section{Conclusion}

It is often assumed that in-depth co-production increases the potential for value co-creation. To test this hypothesis, we have built a computational model of value offering inspired by the model of organizational learning proposed by March (1991[24]). This allows to represent various cases of cocreation: (i) without co-production, (ii) with downstream co-production, and (iii) with upstream co-production. Each case complexifies further the organization's learning system. Overall, simulation results are only partly supporting the hypothesis of the co-creation literature. In one hand, we observe higher organizational performance when consumers are getting more involved into the making of the value offering, but on the other hand it was found that downstream co-production augments inequalities among consumers. Also, simulation results suggest that a relatively low number of consumers should be involved in upstream co-production cases.

This paper highlights the proximity between concepts of value co-creation and organizational learning. Indeed, both are modes of adaptation to a changing environment, whether it is made of competing companies or potential clients. Adopting the point of view of organizational learning imposes to think about co-creation in terms of retro-active loops as the organization can foster change in consumers' aspirations. Such a link is often absent from contributions in terms of value co-creation. On this matter, it is interesting to note that the standard deviations we obtained in terms of consumers' satisfaction provide us with information about their opinion dynamics: downstream scenarios generate more polarized opinions, while upstream ones produce more uniform opinions. Hence, in the present model, the mode of co-production has a significant impact on the dynamics of users' opinions. It would be interesting to investigate the model's behavior when augmented with a more realistic model of opinion dynamics. In such a situation, would upstream co- 
production necessarily lead to consensus and high organizational performance, or would complex opinion dynamics undermine the good performances of the organization?

Besides, value co-creation shows that a change of the indicator of performance can affect significantly the organizational learning process by exposing employees to conflicting information. At first sight, the two archetypal attitudes that have been modeled - i.e. conservative and progressive - were having only a marginal effect on the overall performance of the organization, but they had strong incidence on the different channels composing the learning cycle. For instance, the learning rate of the organization was found to be non-significant in downstream co-production with conservative employees, while it was positive and significant with progressive employees.

This conclusion echoes March and Olsen's argument (1975[26]) that ambiguity threatens the organization's learning cycle by creating viscosities into it. In a sense, changing the performance indicator creates uncertainties for employees, which could hamper their adaptive capabilities and ultimately the one of the organization. To put it another way, contributions in terms of value co-creation often postulate that co-production with users would increase the organization's performance, but this might not be the case if the organization' learning cycle get paralyzed because of ambiguity and conflicting signals coming from the new environment.

In general terms, organizational learning stands out as ubiquitous. Indeed, changes in the organization's performance measures and objectives, in its decision rules and routines, or affecting its environment (clients and competitors) can affect its learning cycle. Consequences for this cycle can be disruptive: loops of learning can switch from positive to negative, with unexpected consequences on the overall performance of the organization. Like many scholars of organizational learning whose contributions have been reviewed in this paper, we believe that such complexity is propitious to the use and development of simulation modelling.

\section{References}

[1] W.B. Arthur. Complexity and the Economy. Oxford University Press, 2015.

[2] D. Ballantyne, P. Frow, R.J. Varey, and A. Payne. Value propositions as communication practice: Taking a wider view. Industrial Marketing Management, 40:202-210, 2011.

[3] D. Breslin. Calm in the storm: Simulating the management of organizational co-evolution. Futures, 57:62-77, 2014.

[4] E. Bruderer and J.V. Singh. Organizational evolution, learning, and selection: A genetic-algorithm-based model. The Academy of Management Journal, 39:1322-1349, 1996. 
[5] K.M. Carley and V. Hill. Structural change and learning within organizations. In A. Lomi and E.R. Larsen, editors, Dynamics of Organizations, Computational Modeling and Organization Theories, chapter 2, pages 63-92. MIT Press, 2001.

[6] M.M. Crossan, H.W. Lane, and R.E. White. An organizational learning framework: From intuition to institution. The Academy of Management Review, 1999.

[7] R.M. Cyert and J.G. March. A Behavioral theory of the Firm. Blackwell Publishers, 1963.

[8] B. Desmarchelier and E.S. Fang. National culture and innovation diffusion. exploratory insights from agent-based modeling. Technological Forecasting and Social Change, 105:121-128, 2016.

[9] N.M. Dixon. The Organizational Learning Cycle, How Can We Learn Collectively. Gower, 1999.

[10] J.M. Epstein. Why model? Journal of Artificial Societies and Social Simulation, 11, 2008.

[11] J.M. Epstein and R. Axtell. Growing Artificial Societies, Social Science from the Bottom Up. Brookings Institution Press, 1996.

[12] J.H. Holland. Adaptation in Natural and Artificial Systems. The University of Michigan, 1975.

[13] J.H. Holland and J.H. Miller. Artificial adaptive agents in economic theory. The American Economic Review, 81:365-370, 1991.

[14] G.C. Kane and M. Alavi. Information technology and organizational learning: an investigation of exploration and exploitation processes. Organization Science, 18:796-812, 2007.

[15] D.H. Kim. The link between individual and organizational learning. Sloan Management Review, pages 37-50, 1993.

[16] M.J. Lanning and E.G. Michaels. A business is a value delivery system. McKinsey Staff Paper, 41, 1988.

[17] T.K. Lant and S.J. Mezias. Managing discontinuous change: A simulation study of organizational learning and entrepreneurship. Strategic Management Journal, 11:147-179, 1990.

[18] T.K. Lant and S.J. Mezias. An organizational learning model of convergence and reorientation. Organizational Science, 3:47-71, 1992.

[19] D.A. Levinthal. Adaptation on rugged landscapes. Management Science, 43:934-950, 1997.

[20] D.A. Levinthal and J.G. March. The myopia of learning. Strategic Management Journal, 14:95-112, 1993.

[21] B. Levitt and J.G. March. Organizational learning. Annual Review of Sociology, 14:319-340, 1988.

[22] T. Levitt. Marketing myopia. Harvard Business Review, 82:138-149, 2004. 
[23] A. Lomi, E.R. Larsen, and F.C. Wezel. Getting there: Exploring the role of expectations and preproduction delays in processes of organizational founding. Organization Science, 21:132-149, 2010.

[24] J.G. March. Exploration and exploitation in organizational learning. Organization Science, 2:71-87, 1991.

[25] J.G. March. Foreword. In A. Lomi and E.R. Larsen, editors, Dynamics of Organizations, Computational Modeling and Organization Theories, pages ix-xvii. MIT Press, 2001.

[26] J.G. March and J.P. Olsen. The uncertainty of the past: Organizational learning under ambiguity. European Journal of Political Research, 3:147$171,1975$.

[27] B. McKelvey. Avoiding complexity catastrophe in coevolutionary pockets: Strategies for rugged landscapes. Organization Science, 10:294-321, 1999.

[28] S.J. Mezias and M.A. Glynn. The three faces of corporate renewal: Institution, revolution, and evolution. Strategic Management Journal, 14:77101, 1993.

[29] M. Mitchell. An Introduction to Genetic Algorithms. MIT Press, 1998.

[30] R.R. Nelson and S.G. Winter. An Evolutionary Theory of Economic Change. Harvard University Press, 1982.

[31] S.P. Osborne, Z. Radnor, and K. Strokosch. Co-production and the cocreation of value in public services. Public Management Review, 18:639653, 2016.

[32] S.P. Osborne and K. Strokosch. It takes two to tango? understanding the co-production of public services by integrating the services management and public administration perspectives. British Journal of Management, 24:S31-S47, 2013.

[33] A.F. Payne, K. Storbacka, and P. Frow. Managing the co-creation of value. Journal of the Academy of Maketing Science, 36:83-96, 2008.

[34] A. Pyka and G. Fagiolo. Agent-based modelling: A methodology for neo-schumpeterian economics. In H. Hanusch and A. Pyka, editors, Elgar Companion to Neo-Schumpeterian Economics, chapter 29, pages 467-487. Edward Elgar, 2007.

[35] S.L. Vargo and R.F. Lusch. Evolving to a new dominant logic for marketing. Journal of Marketing, 68:1-17, 2004.

[36] S.L. Vargo, P.P. Maglio, and M.A. Akaka. On value and value co-creation: A service systems and service logic perspective. European Management Journal, 26:145-152, 2008. 